\title{
DA POSSIBILIDADE DE UMA FENOMENOLOGIA IMPLÍCITA EM KANT E DESCARTES \\ Uma breve perspectiva
}

Urbano Mestre Sidoncha

Universidade da Beira Interior

Instituto de Filosofia Prática

\begin{abstract}
"[...] la phénoménologie continue-t-elle le Transcendantal kantien, [...] le doute et le Cogito cartésiens; elle ne représente aucunement une brusque mutation de la philosophie."
\end{abstract}

\section{Husserl perante Descartes e Kant (Introdução)}

A lacónica afirmação de Paul Ricœur, vertida no passo que inicia o presente trabalho, pela qual se determina que a fenomenologia não figura no repositório das mutações bruscas produzidas em filosofia, é a expressão liminar da tese que versa sobre uma espécie de antecâmara da fenomenologia, na qual ela se teria paulatinamente constituído, na sombra e em silêncio, até cobrar uma significação plena e ser desvelada em sua plenitude. Esse entendimento, seja dito desde já, figura hoje como a expressão última de uma certa linha interpretativa que, mais do que assinalar um certo parentesco entre a filosofia fenomenológica de Edmund Husserl e as filosofias de Descartes e Kant pretende, afinal, obliterar o sentido da absoluta novidade da proposta fenomenológica. A fenomenologia implícita, aquela que teria sido paulatinamente engendrada na sombra por Descartes e Kant, teria, assim, como contraponto, uma fenomenologia explícita, ou antes, uma fenomenologia meramente explicitada por

1 Paul Ricour, À L'École de la Phénoménologie, Paris, J.Vrin, 1987, p. 8. 
Husserl, numa tentativa sempre inacabada que paradoxalmente requer, para a sua consumação plena, um esforço complementar de remissões de sentido permanentes para aqueles que se assim se tomam como seus momentos fundadores.

Uma tal discussão não pode evidentemente ser resolvida aqui. Menos poderá ser resolvida se por ela entendermos um puro esforço de comparação de teses positivas, ou o mapeamento exaustivo das zonas de sobreposição entre as perspectivas que aqui se confrontam: não apenas requer esse exercício um detalhe que não poderíamos dispensar aqui, mas porque um tal exercício aceita como boa a solução que consiste no simples compendiar de diferenças e similitudes.

\section{A relação entre Kant e Husserl pensada a partir do tema do Eu Puro}

Donde, falar da relação entre a fenomenologia husserliana e a filosofia crítica de Kant é um exercício que não se compadece com um ensejo que possa ser determinado na base de uma aproximação superficial, diríamos, residual, entre pontos que figuram, sem celeuma, numa e outra das perspectivas. ${ }^{2}$ Uma tal abordagem, cuja pertinência e legitimidade não devem ser, sem mais, colocadas em questão, inscreve-se pacificamente numa longa tradição de comentário dedicada precisamente à apreciação desta relação entre Kant e Husserl, o que, por si só, não cauciona ainda, como de resto se imporá a um esforço de compreensão que vá mais além deste vulgar jogo de superfície, a preservação dessa relação dialógica em toda a amplitude do seu sentido. Esta omissão é tanto mais grave quanto - se bem interpretamos a essência do movimento fenomenológico engendrado a partir de Husserl - é a partir dela que a fenomenologia se projecta como uma perspectiva nova e radical.

Para colmatar esse hiato, importa, pois, pensar um primeiro ponto de intersecção entre fenomenologia e kantismo a partir de uma discussão que seja, em si mesmo, indiciadora dessa relação, ainda que tomada na sua expressão mais balbuciante: falamos do tema do Eu Puro. Na apreciação deste ponto estão condensados, com estranha simultaneidade, os factores de proximidade e divergência entre Kant e Husserl, e portanto, a apreciação daquilo que emerge, no quadro desse debate fundador para a fenomenologia, como a positio quaestionis da própria disciplina de Husserl.

É bem conhecida a fraca estima que o trabalho de Kant colheu, inicialmente, junto de Husserl. A tal situação não será seguramente alheia a forma como Husserl acedeu à filosofia kantiana, veiculada principalmente através

${ }^{2}$ Esse parece ser de resto o preço a pagar sempre que está em causa um confronto crítico entre as duas perspectivas: "La parenté de Kant et de Husserl n'est [...] atteinte qu'au prix d'une abstraction légitime, mais précaire, pratiquée sur l'intention totale de l'une et de l'autre œuvre." Ibidem, p. 237. 
das leituras de Franz Bolzano. ${ }^{3}$ Essa situação seria posteriormente invertida, embora nunca definitivamente superada, pela influência, desta feita, de eminentes figuras do neo-kantismo coevo, das quais se destaca, claramente, Paul Natorp. ${ }^{4}$

Se é, porém, certo que esse distanciamento não permaneceu, não deixa igualmente de ser curioso o facto de se apontar comummente a data de 1917 como ponto de viragem para a anuência e simpatia crescentes de Husserl relativamente a alguns tópicos do kantismo. ${ }^{5}$ Essa curiosidade sobrevém apenas nesta simples consideração: se a fenomenologia se consolidou, genericamente, entre os anos de 1900-01 (data da primeira edição das Logische Untersuchungen) e 1913 (ano da publicação do primeiro volume de Ideen zu einer reinen Phänomenologie und phänomenologischen Philosophie), situar a influência do kantismo numa fase posterior ao próprio amadurecimento da fenomenologia e à consumação plena desse período de interna maturação é certificar, inequivocamente, uma menor ascendência da filosofia kantiana para a emergência e solidificação de uma orientação especificamente fenomenológica. Esta suspeita vem de resto engrossar o caudal dos comentários que apontam o cartesianismo, mais que o kantismo, como matriz essencial sobre a qual repousam os fundamentos da disciplina fenomenológica. ${ }^{6}$ No entanto,

3 "[...] Husserl did not really come in contact with Kant's philosophy before he met Franz Brentano. The latter [...] had come to a very negative attitude toward Kant and was probably the leading Kant critic in the last two decades of the nineteenth century. Husserl adopted Brentano's views on Kant without personal study of Kant's works [...]" Joseph J. Kockelmans, "Husserl and Kant on the Pure Ego", in Husserl-Expositions and Appraisals, Ed. by Frederick A. Elliston \& Peter MC Cormick, Notre Dame, London, University of Notre Dame Press, 1977, p. 269. Esta relação entre a próximidade de Husserl relativamente a Brentano, e a fraca estima do último em relação a Kant, é também sublinhada por João Vila-Chã: "Foi [...] sobretudo marcado pela busca de uma nova autojustificação da filosofia, que Husserl deixou acontecer em si o decisivo encontro com o pensamento de Franz Brentano [...]. Franz Brentano [era] conhecido também pela sua pouca estima por Kant e o Idealismo Alemão [...]." João Vila-Chã, "Edmund Husserl (1859-1938)", Revista Portuguesa de Filosofia, Tomo XLIV, Fasc. 3, Braga, Editora Correio do Minho, 1988, p. 360.

4 Uma tal proximidade esteve, aliás, na origem de uma certa tradição de comentário, que insistia justamente na estreita proximidade entre as obras de ambos os autores como factor que, de alguma forma, diluía a novidade do discurso husserliano. R. Ingarden regista uma tal tradição: "[...] Husserl was often accused on the grounds of similarities between his Ideas and Natorp's Allgemeine Psychologie of 1912." Roman Ingarden, On the Motives which led Husserl to Transcendental Idealism (Trans. From Polish by Arnor Hannibalsson), The Hage, Martinus Nijhoff, p. 13.

5 Essa é também a leitura de Joseph Kockelmans: "In 1917 Husserl turned again to Kant's philosophy, and this time the renewed contact with Kant and the neo-Kantian tradition was to begin to influence Husserl's own thought [...]. The direct influence of Kant and the neoKantians became, from then on, more and more perspicuous in Husserl's work [...]."Joseph J. Kockelmans, "Husserl and Kant on the Pure Ego", in Husserl-Expositions and Appraisals, Ed. by Frederick A. Elliston \& Peter MC Cormick, Notre Dame, London, University of Notre Dame Press, 1977, pp. 269-270.

6 Atentemos de novo nas palavras claras e oportunas de Joseph Kockelmans: "[...] his [Husserl's] original conception of phenomenology (as found in the second volume of Logical 
esta situação que ora se lê como uma clara certificação da insuperável diferença que aparta Husserl de Kant pode, curiosamente, ser lida noutro e diametralmente oposto sentido: até que ponto não é, precisamente, essa putativa convergência entre o criticismo de Kant e a fenomenologia transcendental de Husserl que levaram este último a evitar, tanto quanto possível, uma referência ao primeiro, evitando, assim, esgotar os motivos e os métodos da fenomenologia em uma perspectiva com créditos já firmados? ${ }^{7}$ Há, no entanto, outras possibilidades hermenêuticas menos exuberantes, ou mais circunstanciadas, para interpretar esta aparente relutância em filiar a fenomenologia na filosofia kantiana - ou em qualquer outra perspectiva "positiva" -, e que colhe a sua génese na essência mesma de uma fenomenologia marcada, desde o nascimento, pelo desejo de fundamentação última e radical. ${ }^{8}$ É que uma tal radicalidade congénita do empreendimento fenomenológico, tal qual fora arquitectada pelo seu mentor, não se compadece com a figura da "inscrição", e menos ainda com a da "subsunção" em uma qualquer doutrina concreta (não obstante a existência, de resto plenamente assumida, de zonas de sobreposição), seja o kantismo ou qualquer outra, mas na própria ideia de uma filosofia que se põe como ciência de fundamentação radical. Notemos, pois, que a verificar-se esta verberada coincidência entre fenomenologia e a filosofia crítica de Kant, ficaria afectada, diríamos mais, irremediavelmente comprometida, a decisão teórica de fundo que marca o nascimento da disciplina de Husserl, não evidentemente por se tratar de um autor mais ou menos próximo das posições husserlianas, mas justamente pela circunstância de se tratarem de manifes-

Investigations) to transcendental phenomenology, first explained in a series of lectures in 1907 and latter systematically developed in the firs volume of Ideas in 1913, had come about the influence of Descartes [...] rather than trough the philosophy of Kant." Joseph J. Kockelmans, "Husserl and Kant on the Pure Ego", in Husserl - Expositions and Appraisals, Ed. by Frederick A. Elliston \& Peter MC Cormick, Notre Dame, London, University of Notre Dame Press, 1977, p. 269. São igualmente oportunas as condiderações de Gaston Berger, que situa, justamente, no tema do cogito a evidência da maior preponderância do cartesianismo na fenomenologia: "Kant, Descartes et Husserl ont toutes les trois réfléchi sur le cogito, mais l'attitude, la méthode, l'intention nous paraissent très semblables chez les deux derniers, très différentes chez Husserl e chez Kant" Gaston Berger, Le Cogito dans la Philosophie de Husserl, Paris, Éditions Montaigne, p. 122.

7 " [...] although it is true that Husserl gradually learned to appreciate the greatness of Kant's work and began to realize that there was a great affinity between Kant's transcendental philosophy and his own transcendental phenomenology, he always tried to avoid giving the impression that his own philosophy originated from Kant's philosophy or even should be understood from the perspective of the entire Kantian tradition." Joseph J. Kockelmans, "Husserl and Kant on the Pure Ego", in Husserl - Expositions and Appraisals, Ed. by Frederick A. Elliston \& Peter MC Cormick, Notre Dame, London, University of Notre Dame Press, 1977, p. 270.

8 "Husserl viveu toda a vida, desde que começou a estudar Astronomia até se doutorar em Matemática e finalmente se dedicar à Filosofia, dominado pela ânsia duma fundamentação rigorosa do saber humano. Chegou à Filosofia precisamente porque aí se lhe evidenciou o âmbito necessário para tal fundamentação." Júlio Fragata, Problemas da Filosofia Contemporânea, Publicações da Faculdade de Filosofia da UCP, Braga, 1989, p. 58. Itálicos nossos. 
tações particulares, logo unilaterais, logo ainda, parciais e não-universais, como seria próprio de uma fenomenologia qua ciência filosófica fundamental. Seja, pois, dito, agora liminarmente, que qualquer tentativa para surpreender o kantismo da fenomenologia não pode ignorar que, a existirem (como efectivamente parece crível) tais influências, elas devem ser sempre "filtradas", "purificadas", exauridas da sua unilateralidade, e reintegradas num movimento radical e, como tal, universal. $^{9}$

Todavia, e afirmada assim liminarmente, esta purificação não se distancia da ideia do "simplesmente programático", assumindo-se como uma afirmação vaga, formal, incapaz, pois, de estabelecer vínculos concretos e efectivos. Dito de outra forma, a consideração desta derradeira alternativa para aceder ao significado último do hiato entre fenomenologia e kantismo exige, como sua condição mesma de possibilidade, que se exibam os "pontos" concretos onde tais disciplinas se tocam, e em que medida essa "apropriação" não assoma como uma simples "sobreposição" (que alimenta, como foi dito, a segunda das alternativas hermenêuticas que apresentámos atrás). Isso significa, por outro lado que, por cada marca de filiação, de proximidade, encontraremos outros tantos indícios de dissidência, que mais não são, no entanto, que a expressão visível do esforço antes referido de "purificação". Se é, pois, verdade que os motivos essenciais de uma fenomenologia - pensados a partir das máximas de fundamentação e rigor, do tema reitor de uma "crítica da razão" ou ainda da afirmação do tópico de uma subjectividade constituinte - não são totalmente estranhos ao espírito de uma filosofia crítica (e tudo isso configura, como é bem compreensível, importantes pontos de aproximação), não é menos verdade que o criticismo de Kant pode, com verdade, e à luz dos pressupostos metodológicos ulteriormente definidos pela fenomenologia, considerar-se ensombrado ainda por uma flagrante ausência de radicalidade. Essa falta assinala novamente, depois de apurado um inicial motivo de convergência, um derradeiro sinal de distanciamento, o que para uma fenomenologia madura só pode significar a contumaz presença de inaceitáveis elementos transcendentes (ou, na nomenclatura própria da fenomenologia, de elementos transcendentes relativamente à consciência). Impõe-se, pois, que averiguemos as circunstâncias que tornam visíveis esses ínvios "sinais" de uma atitude "mundana", que imediatamente converteram os laços do que parecia ser um sólido parentesco em sinais de uma irrecuperável dissidência. Renunciando a qualquer pretensão de exaustividade, enumeremo-las de forma breve.

9 É aliás a mesmíssima razão que impede, por exemplo, que se fale de uma fenomenologia "portuguesa" ou "alemã". Isso mesmo observou, com particular clareza, Pedro Alves: "Nada pode haver mais contrário ao espírito da fenomenologia de Edmund Husserl que falar de uma fenomenologia "alemã", "francesa" ou também ainda "portuguesa". A fenomenologia pretende ser uma ciência desenvolvendo-se no elemento da mais estrita universalidade e decididamente afastada de qualquer particularismo cultural ou nacional". Pedro Alves, "A Fenomenologia em Portugal", in História do Pensamento Filosófico Português - Volume V: O Século XX, Ed. Caminho, (Direcção de Pedro Calafate), Lisboa, 2000, p. 345. 
Desde logo,

i) o criticismo institui-se numa base que elege como factos ciências positivas para depois perguntar pelas suas condições de possibilidade, ignorando que o "ser facto" se põe precisamente como "problema que demanda solução". ${ }^{10}$ Mais,

ii) essa "transcendência" é, por sua vez, "[...] explicada por actos da subjectividade, como as faculdades da sensibilidade e do entendimento, onde o sujeito se pressupõe como sujeito de faculdades psíquicas", ${ }^{11}$ logo, por uma segunda e igualmente inaceitável transcendência, ${ }^{12}$ desta feita, no "coração" da actividade crítica, que não pode inscrever-se noutra coisa que não seja numa subjectividade transcendental, que é o único "absoluto" que a fenomenologia pode coerentemente assumir. ${ }^{13}$ A subjectividade da fenomenologia pretende-se "instituidora" da objectividade, o que não é compaginável com a dependência dessa subjectividade relativamente à objectividade que lhe compete instituir. Esta última consideração traça o caminho para uma terceira transcendência do kantismo, ou, segundo os critérios já expendidos, de um terceiro factor de dissidência entre a filosofia crítica e a fenomenologia. Efectivamente,

iii) no início do processo da Erkenntnis está, aparentemente, segundo Kant (ou pelo menos, segundo o texto expendido na Estética Transcendental) - curiosamente a "[...] parte menos fenomenológica da Crítica", segundo P. Ricœur ${ }^{14}$ ) - a afecção de um objecto, exterior à consciência e anterior a qualquer função sintética do entendimento, e portanto, "independente" da actividade de uma subjectividade que Kant deseja colocar, sob a sigla da revolução coperniciana, no centro

10 Vide Gustavo de Fraga, De Husserl a Heidegger - Elementos para uma Problemática da Fenomenologia, Universidade de Coimbra, 1966, p. 23.

11 Ibidem, p. 23.

12 " [...] Husserl claims that in the Critique the faculties of the ego and all the functional laws are derived from the natural reality of the subject taken as this human person; thus Kant failed to make a distinction between the ego as this real man in the world and the pure ego." Joseph Kockelmans, "Husserl and Kant on the Pure Ego", in Frederick A. Elliston \& Peter MC Cormick, Husserl - Expositions and Appraisals, Notre Dame / London, University of Notre Dame Press, 1977, p. 276.

13 "A subjectividade transcendental é o único absoluto que a fenomenologia aceita, porque a redução fenomenológica desvinculou o mundo natural e o do espírito, as ciências da natureza e a ciências do espírito, bem como os seus resultados, e inclusivamente a transcendência de Deus, que seria um outro absoluto, não só em frente do mundo, mas da consciência absoluta". Gustavo de Fraga, De Husserl a Heidegger - Elementos para uma Problemática da Fenomenologia, Universidade de Coimbra, 1966, p. 17.

14 " $L$ 'Esthétique transcendantale est sans doute la partie la moins phénoménologique de la Critique [...].”Paul Ricœur, À L'École de la Phénoménologie, Paris, J. Vrin, 1987, p. 232. 
do processo de conhecimento. A ser rigorosa uma tal interpretação das condições que asseguram a legitimidade do conhecimento, ela não pode ser interpretada senão como um novo e declarado exemplo de exterioridade, e essa exterioridade vê-a a fenomenologia, uma vez mais, como um sinal da transcendência que o filósofo de Freiburg tanto reprova. De facto, nada mais contrário a uma fenomenologia transcendental, mas ao mesmo tempo, nada mais contrário ao próprio espírito que anima uma filosofia crítica, que a tese de uma Ding an sich que engendra um espaço de exterioridade que, pela natureza mesma das coisas, não pode ser contido sem perigo de minar o campo do fenomenológico que, como antes fizemos notar, se não institui sem a sua prévia "suspensão".

Não terminam ainda aqui, todavịa, os motivos que permitem haurir, no espaço desta escrutinada relação dialógica, o dissídio de fundo entre as perspectivas sustentadas por Kant e Husserl:

iv) a própria ideia de transcendentalidade merecerá um tratamento diferenciado em cada um dos respectivos autores. Desde logo, se perspectivarmos o domínio do transcendental pela negativa, quer dizer, como contraponto a qualquer outro domínio, essa diferença entre ambos sobressai prontamente: para Husserl, "transcendental" é aquilo que se opõe a mundano, enquanto que, para Kant, transcendental é o contraposto do "empírico". ${ }^{15}$ A própria concepção de consciência, já se adivinha, merecerá igualmente um tratamento muito diferenciado nos dois autores: contra Kant, a consciência em Husserl não é posto como conceito aglutinador das condições formais de direito. Mas também não é, como aventará Descartes (a quem nos reportaremos oportunamente) res, nem mesmo a human mind de John Locke, que vem imediatamente na sua esteira. O conceito de consciência que é manejado por Husserl põe-se simultaneamente como um conceito concreto (contra Kant) e ideal (contra Descartes).

Tais diferenças, que aqui se assinalam na sua expressão mais elementar, podiam estender-se quase indefinidamente, contribuindo, dessa forma, para corromper a tese de uma suposta, mas nunca efectivamente provada, principialidade do kantismo relativamente ao objecto da fenomenologia. No entanto, a pura ausência de prova parece não ser suficiente para vencer a linha de interpretação que toma o idealismo transcendental de Kant como uma fenomenologia implícita. Esse é, por exemplo, o entendimento de Paul Ricœur, que

15 "Les confusions qui pourraient se produire à propos du «transcendental» sont encore plus graves. Comme le remarque M. Fink, ce terme s'oppose chez Kant à «empirique», chez Husserl à «mondain»." Gaston Berger, Le Cogito dans la Philosophie de Husserl, Paris, Éditions Montaigne, p. 123. 
perspectiva a fenomenologia husserliana como mera continuação do substrato fenomenológico em que está hipostaseado todo o edifício da crítica kantiana. Recuperemos aqui essa tese: "[...] discernimos, na base da epistemologia kantiana, uma fenomenologia implícita relativamente à qual Husserl seria, de alguma forma, o seu proclamador. Nesse sentido, Husserl prossegue qualquer coisa que estaria impedida e que permanecia num estado embrionário. [...] perguntamo-nos se a fenomenologia de Husserl não representa o desvelamento de uma fenomenologia implícita em Kant [...]".16 Apesar de imediatamente atractiva, uma tal concepção deixa na sombra um aspecto que não pode ser desatendido: ler o idealismo transcendental de Kant como uma expressão que é, de jure, fenomenológica, é sustentar que a fenomenologia tem um começo que está a montante da própria fenomenologia, não apenas a título de uma mera "antecedência" titubeante, mas como esboço efectivo da disciplina, a que Husserl mais não fará do que "emprestar" a sua forma explícita e definitiva. Ora, uma tal consideração deixa na sombra a novidade radical que assoma como marca singular da tematização husserliana, e que está intimamente associada ao instrumento da redução fenomenológica, aquele que é, justamente, o passo metodológico que "[...] faz surgir o para mim de toda a posição ôntica". ${ }^{17}$ Ora, a redução não pode ser vista com sobranceria, como se de um apêndice de valor discutível se tratasse, já que ela é, na verdade, a base imprescindível sobre a qual emerge e se institui o campo próprio da fenomenologia. Com efeito, "[...] o para mim é desde o princípio dissimulado pela própria posição do ente; é esta posição dissimulante que Husserl chama atitude natural (ou tese geral do mundo) [...]". ${ }^{18} \mathrm{O}$ fenómeno do mundo, isto é, a sua recondução àquilo que existe em primeira instância como sentido na consciência, só se alcança em sentido pleno chamando à colação esse princípio primordial da redução fenomenológica, que figura indiscutivelmente como uma das marcas mais preponderantes da fenomenologia husserliana. ${ }^{19}$ Donde, o percurso que

16 “[...] nous discernerons, derrière l'epistémologie kantienne, une phénoménologie implicite dont Husserl será en quelque sorte le révélateur. En ce sens Husserl continue quelquer chose qui dans le kantisme était empêché et restait à l'état embryonnaire, bien que cela fût nécessaire à son économie générale. [...] nous nous demanderons si la phénoménologie de Husserl ne represente pás a la fois l'épanouissement d'une phénoménologie implicite chez Kant [...]." Paul Ricœur, A L'École de la Phénoménologie, Paris, J.Vrin, 1987, p. 227.

17 Pela sua importância, recuperamos na íntegra o passo supramencionado: "Dans son intention strictement méthodologique, lá réduction est une conversion qui fait surgir le «pour moi» de toute position ontique." Ibidem.

18 "[...] le «pour moi») est d'abord dissimule par la position même de l'étant; cette position dissimulante que Husserl appelle attitude naturelle (ou thèse générale du monde) [...]". Ibidem, p. 228.

19 Será oportuno, nesta ocasião, atentar nas oportunas palavras de Eugen Fink: "Si une théorie doit toujours être comprise au regard du problème dont elle veut être la maîtrise théorétique (ce qui manifeste le motif de la théorie), alors la phénoménologie entraîne d'entrée de jeu une certaine «incompréhensibilité», puisqu'on ne peut en comprendre le principe au regard du problème mondain, c'est à dire au regard de tout ce qui est questionnable dans l'horizon de l'«attitude naturelle». Son problème fondamental est caché, en ce sens qu'il n'est pas présent comme problème avant la théorie phénoménologique [...] mais qu'il se forme dans et par 
a fenomenologia nos permite fazer é, justamente, o que vai daquilo que poderíamos designar de "absolutização do ôntico" 20 à "absolutização do eu", do fluxo de consciência. ${ }^{21} \mathrm{O}$ próprio Ricœur, independentemente do juízo que deve ser feito sobre a forma como joga o destino da fenomenologia numa pura diferença entre aparecer e ser, reconhecerá nesta transição a conquista essencial da fenomenologia: "A glória da fenomenologia é ter elevado à dignidade de ciência, pela 'redução', a investigação do aparecer." 22

la réduction phénoménologique, première étape de sa maîtrise. Ce n'est qu'en transcendant le monde qu'on peut esquisser le problème «transcendantal» du monde." Eugen Fink, De la Phénoménologie, (trad. de Didier Franck), Les Éditions de Minut, p. 126.

20 Essa perspectiva é sublinhada por R. Ingarden: "From the positions of his later idealism Husserl protests against the 'absolutization' of the real world. This means that the existence which is only 'for' the conscious subject and does not possess its own essence is not to be considered as a being 'in itself' which is endowed whit its own effective essence. This "in itlself' (an sich) is [...] something which belongs to the real world if it is considered 'absolutized' or [...] as Husserl says in the Ideas [...] take up the natural attitude." Roman Ingarden, On the Motives which led Husserl to Trancendental Idealism (Trans. from Polish by Arnór Hannibalsson), The Hague, Martinus Nijhoff, 1975, p. 5. Itálicos nossos. As considerações aqui gizadas são da maior relevância para a compreensão do bem conhecido tópico do "idealismo de Husserl", que aqui não poderemos tratar.

21 "La réduction fait apparaître la conscience non seulement comme radicalement distincte de la réalité objective, mais encore comme «être absolu, en ce sens que par principe nulla re indiget ad existendum», alors que le monde des choses "se rapporte entièrement à une conscience» [...] actuelle, vivante." Lothar Kelkel, René Schérer, Husserl - Sa Vie, son Oeuvre avec un exposé de sa Philosophie, Paris, Presses Universitaires de France, 1964, p. 56. Noutra passagem igualmente sugestiva, pode ler-se: "[...] the transcendental reduction "inverts the whole-part relationship, so that after its performance, the ultimate horizon is subjectivity or consciousness. That is to say, consciousness is no longer viewed as a part of a worldly 'whole'; instead, it is viewed as a 'whole' of which the world is a part. Consciousness is now everything, not just 'a little tag-end of the world'; and the world is now something essentially related, i.e. 'relative', to consciousness. In short, after the transcendental reduction, what remains is absolute consciousness and the relative being of the world." Matheson Russel, Husserl: A Guide for the Perplexed, London/New York, Continuum, 2006, p. 71.

Outra das questões candentes na apreciação do idealismo da fenomenologia é, justamente, a da determinação do significado dos termos que atrás referimos de "relativo" e "absoluto". Assim, pergunta-se: qual o alcance exacto da afirmação do relativismo do mundo e do carácter absoluto da consciência? A resposta, porém, não tem uma feição unívoca, porquanto acompanha o próprio sentido associado ao processo de interna evolução da fenomenologia. Para uma abordagem célere, mas incisiva. $\mathrm{Cf}$. Theodore de Boer, The Development of Husserl's Thought, Trad de Theodore Plantinga, The Hage/Boston/London, Martinus Nijhoff, 1978, pp. 341-350. Apesar dessa multiplicidade de acepções, é possível precisar, nestas circunstâncias, o sentido estrito do termo "absoluto", quando este qualifica a consciência e, conversamente, do termo "relativo", que caracteriza o mundo: "[...] it is a question of dependence. The sense of reality is dependent on subjectivity because only subjectivity is capable of giving sense; consciousness, on the other hand, is not dependent on something outside of itself that gives it its sense. It has its sense in itself, it is absolute. Here, the absolute is contrasted to the relative, to what which depends on something else for its sense." Robert Sokolowsky, The Formation of Husserl's Concept of Constitution, The Hague, Martinus Nijhoff, 1970, pp. 129-130. Itálicos nossos.

22 "La gloire de la phénoménologie est d'avoir élevé à la dignité de science, par la «réduction», l'investigation de l'apparaître." Paul Ricœur, À L'École de la Phénoménologie, Paris, J. Vrin, 1987, p. 250. Itálicos nossos. 


\section{O "cartesianismo" de Husserl}

A relação entre Husserl e Descartes, tomada liminarmente na pura forma da sua enunciação, denuncia já uma relação que é decisiva para a interna consolidação da orientação fenomenológica. Esta afirmação, que institui a tese de um cartesianismo de Husserl e da própria fenomenologia (independentemente do sentido último que se lhe queira emprestar) traz ainda na sombra uma referência ao transcendental kantiano, lançando novamente a dúvida se não deve ser a filosofia crítica de Kant, mais do que o cartesianismo, a merecer esse reconhecimento de marca fundamental que prefigura o objecto e o estilo da fenomenologia. ${ }^{23}$ Por outras palavras, não é a filosofia transcendental, que é uma das indeléveis conquistas da filosofia kantiana, uma marca mais perene para a fenomenologia? Porquê insistir, nesse caso, num suposto "cartesianismo da fenomenologia"? Como deve ser lido, ou qual o seu significado último para a disciplina de E.Husserl? ${ }^{24}$

Seja dito, todavia, que o repositório das múltiplas convergências doutrinárias que se deixa instituir como símbolo de uma absoluta proximidade entre os dois pensadores - ao contrário, por exemplo, do que sucede no exercício análogo de aproximação ao criticismo kantiano - não se deixa estabelecer por nenhuma tradição de comentário apostada em ver, na fenomenologia, uma simples repetição ou a mera prossecução das orientações filosóficas já antecipadas pelo cartesianismo; é antes o próprio Husserl quem assume, sem reservas, uma profunda admiração pelo pensador francês, ${ }^{25}$ e quem explicitamente reconhece um certo parentesco entre as perspectivas gizadas por ambos. ${ }^{26}$ Pese embora um tal reconhecimento, devemos suspeitar se essa putativa filiação da fenomenologia no cartesianismo - e que o próprio Husserl

23 Um cabal tratamento deste capítulo das "influências" de Husserl não ficará completo sem uma avaliação da relação - tomada por muitos intérpretes da fenomenologia husserliana como decisiva para a compreensão de algumas das teses matriciais da disciplina - entre o próprio Husserl e Hume. Para um estudo mais incisivo sobre essa importante relação, vide Richard Murphy, Hume and Husserl, The Hague, Nijhoff, 1980.

24 A mesma questão se coloca Ricœur: "il peut parâitre étrange que Husserl s'attarde davantage à [...] Descartes qu'à Kant. Kant n'est-il pas le philosophe transcendantal par excellence, selon son propre vocabulaire?" Paul Ricœur, À L'École de la Phénoménologie, Paris, J. Vrin, 1987, p. 46.

25 De entre as inúmeras referências constantemente produzidas e reelaboradas por Husserl, onde expressa justamente esta proximidade em relação a Descartes, eis algumas das mais sintomáticas: "[...] kein Philosoph der Vergangeheit hat auf den Sinn der Phänomenologie so entsheidend wie Frankreischs größter Denker, René Descartes. Ihn muß sie als ihren eigentlichen Erzvater verehren. Ganz direkt [...] hat das Studium der Cartesianischen Meditationen in die Neugestaltung der werdenden Phänomenologie eingegriffen und ihr diejenige Sinneșform gegeben, die sie jetzt hat und die ws fast gestattet, sie einen neunen Cartesianismus zu nennen, einen Cartesianismus vom 20. Jahrhundert." E. Husserl, P. V, Husserliana, Band I, p. 3.

26 Vimos, na secção anterior, que o mesmo reconhecimento não é dedicado a Kant. A este respeito, pergunta Ricœur: "pourquoi tant de réticences dans l'éloge de Kant, à Vienne et à Prague?"Paul Ricœur, À L'Ecole de la Phénoménologie, Paris, J.Vrin, 1987, p. 46. 
parece por vezes sustentar - não resultará mais de uma vontade em encontrar, na história da filosofia, uma orientação com uma expressão unívoca, e que teria o seu início justamente em Descartes, do que propriamente uma realidade que se vê plenamente sustentada pela substância dos textos. É bem verdade que é sempre possível estabelecer parentescos pontuais, e muitos deles decisivos, entre a filosofia da consciência de Descartes e a fenomenologia de Edmund Husserl. Porque justamente não se trata de fazer a geografia das zonas de sobreposição, permitimo-nos elencar apenas duas. Desde logo,

i) deve-se ao primeiro a "descoberta" da necessidade de uma reflexão radica ${ }^{27}$ e, em consequência disso, a afirmação do primado da consciência sobre todos os seus objectos. ${ }^{28}$

ii) a via reflexiva, que assim se deixa inaugurar, constitui igualmente um espólio em relação ao qual a fenomenologia se pode explicitamente assumir como herdeira, na medida em que é uma tal abordagem que lhe permitirá instaurar, por vez primeira, e de forma plenamente consequente, uma descontinuidade relativamente ao terreno da atitude natural.

Mas se isso é verdade, não é menos certo que esse exercício de sucessivas importações de sentido pode ser sumariamente interrompido, instituindo-se uma linha de interpretação outra que liminarmente afasta a tese da simples reedição da filosofia de Descartes como pulsão decisiva para a descoberta da própria fenomenologia. Tal significa, outrossim, que sustentar a tese da interpretação regressiva da fenomenologia seria, efectivamente, uma inopinada confissão da total incompreensão em relação aos motivos de fundo que estão na génese mesma do empreendimento husserliano. Prevalece aqui o princípio que já antes fora dirigido ao estudo comparativo das perspectivas de Husserl e Kant: por maior que seja a afinidade entre as respectivas orientações, a fenomenologia não depende de nenhuma orientação concreta, nem se exibe como desenvolvimento de um programa cujos motivos se situam a montante. Husserlianamente falando, o que é próprio da fenomenologia é justamente uma exigência de radicalidade que é absolutamente inconciliável com a assunção de qualquer tipo de filiações concretas, hauridas ao nível de teses positivas que apressadamente se agitam como sinal de um parentesco efectivo e duradoiro.

Dito isto, importa fazer notar ainda que não é da assunção deste princípio formal, que versa sobre a impossibilidade de filiação ou dependência de uma

27 "Es bedarf eines radikalen Neubaues, der der Idee der Philosophie als universaler Einheit der Wissenschaften in der Einheit einer absolut rationalen Begründung genugtut." Edmund Husserl, P. V, Husserliana, Band I, p. 3. Itálicos nossos.

28 "Descartes inauguriert [...] eine völlig neuartige Philosophie. Diese nimmt, ihren gesamten Stil verändernd, eine radikale Wendung vom naiven Objektivismus in einen transzendentalen Subjektivismus, der in immer neunen und doch immer ungenügenden Versuchen zu einer reinen Endgestalt hinstrebt." Ibidem p. 5. 
perspectiva que se diz radical em relação a qualquer outra que se põe na sua base, que resulta a incapacidade em estabelecer laços mais efectivos e duradoiros com o cartesianismo. Dito de outra forma, a declaração de que a fenomenologia é um empreendimento radical não é qualquer coisa que valha per $s e$, mas antes um princípio cuja legitimidade deve ser haurida nos textos dos respectivos autores. $\mathrm{O}$ constrangimento que corta cerce essa possibilidade de fusão, e que foi sendo sistematicamente aventado como possibilidade hermenêutica para aceder ao sentido último da fenomenologia não é, pois, um constrangimento "extrínseco", que resulta da observância de qualquer coisa que esteja para lá das teses filosóficas em causa, mas é, ao contrário, algo que brota espontaneamente dos próprios textos, e que sustentam, agora com uma legitimidade nova e reforçada, a declaração inicial que versava justamente sobre a impossibilidade de radicar a fenomenologia em qualquer doutrina particular. Como bem notou Paul Ricœur, se o cartesianismo é esse empreendimento marcado por uma exigência de radicalidade na qual se veria imediatamente um nexo de proximidade com a fenomenologia, será a intimação mesma dessa radicalidade que marcará, $a b$ initio, o primeiro grande dissídio - e provavelmente aquele com consequências mais expressivas - entre Husserl e Descartes, se considerarmos, outrossim, que foi o próprio Descartes quem liminarmente se escusou à assunção última do alcance filosófico desse princípio fundamental, cuja "paternidade" antes se lhe atribuía ${ }^{29}$, fazendo dele - para utilizar uma célebre expressão de Husserl - o Vater des widersinnigen transzendentalen Realismus. Assim, como observa ainda Ricœur, se é verdade que é a Descartes que pode ser imputada a descoberta do motivo transcendental ${ }^{30}$ onde, temo-lo dito repetidamente, a fenomenologia determinará o espaço que é legitimamente o seu ${ }^{31}$, é igualmente verdade que o "estranho destino do cartesianismo" o levará a promover perspectivas - como os racionalismos de Malebranche, Espinosa, Leibniz eWolff, ou o empirismo céptico - que, de uma forma ou de outra, dissolvem as marcas fundamentais que estão, na fenomenologia, indelevelmente associados a um tal motivo transcendental ${ }^{32}$.

29 “C'est à Descartes qu'il faut rapporter la première réflexion radicale sur la priorité de la conscience sur tous ses objets; à ce titre, il est le fondateur du motif transcendantal, seul capable de ruiner la naïveté dogmatique du naturalisme [...]"

"[...] Mais Descartes fut le premier à se trahir lui-même. [...] le je du pense est compris comme la réalité psychologique [...]." Paul Ricœur, A L'École de la Phénoménologie, Paris, J. Vrin, 1987, p. 45.

${ }^{30}$ Ricœur segue, neste ponto, de forma próxima, a letra dos próprios textos de Husserl: "Jedenfalls bezeichnet sich damit der Weg, der zur transzendentalen Phänomenologie geführt hat." Edmund Husserl, P. V, Husserliana, Band I, p. 5.

31 Vide Urbano Sidoncha, "A Fenomenologia perante o problema da compreensão do Homem Verdadeiro", in Arbor, revista de Ciência, Pensamiento y Cultura, vol. CLXXXV, n 736 , La vigencia de la fenomenologia -, Consejo Superior de Investigaciones Científicas (CSIC), Madrid, 2009.

32 “"...] l'étrange destin du cartésianisme, qui engendra [...] le rationalisme de Malebranche, de Spinoza, de Leibniz, de Wolff, tout entier tourné vers a connaissance absolue de l'être en soi, 
Assim, se é, pois, certo que o suporte motivacional que concita o percurso cartesiano é o que se deixa consubstanciar numa "vontade radical de ausência de preconceitos ${ }^{33}$, que é a base a partir da qual se engendra o horizonte de sentido da própria filosofia transcendental, tal como fora originariamente arquitectada por Husserl, é igualmente certo que esse espírito foi atraiçoado pela assunção de determinados pressupostos que, independentemente da bondade da decisão teórica de fundo que esteve na sua origem, estão ainda nos antípodas de uma perspectiva que justamente vê nesses compromissos - invariavelmente assumidos à revelia da exigência de radicalidade que se impunha - resquícios seguros de uma abordagem que, tendo inaugurado o espaço do transcendental, não transpõe verdadeiramente a porta de entrada que lhe dá acesso ${ }^{34}$. Nesta afirmação se joga, digamo-lo uma vez mais, a peculiar compreensão das complexas relações entre Descartes e Husserl: de um lado, a assunção plena do impulso que foi capaz de colocar o acento tónico da investigação filosófica, a partir de então concebida como radical, na subjectividade transcendental, com prejuízo, e em detrimento, de um anacrónico objectivismo ingénuo; de outro, a chamada a si da "prudência" como instrumento filosófico, de forma a evitar os erros "que nem o próprio Descartes soube evitar"35. Esta tensão, sempre latente, e nunca plenamente resolvida a favor de um dos lados da contenda é, pois, uma das marcas mais perenes da fenomenologia husserliana, que percorre transversalmente o conjunto dos textos do célebre "período transcendental" de Husserl.

Trata-se, aliás, de uma situação que influiu igualmente na forma mesma como fomos interpretando, ao longo deste trabalho, o significado do cartesianismo da fenomenologia, num testemunho disperso e difuso que é, de sua vez, o mais insuspeito depoimento da multiplicidade das manifestações que uma tal "herança" assumiu no percurso que levou, poder-se-ia dizê-lo, a uma clara emancipação da fenomenologia relativamente a ela própria, mesmo - diríamos, principalmente - nos casos em que desse confronto resulta um distanciamento crítico. Colhe-se assim, e em sentido pleno, o verdadeiro alcance filosófico deste pretenso cartesianismo da fenomenologia: "um «cartesianismo» da fenomenologia só [...] se pode revelar no seu significado [...] não como um retornar ao momento cartesiano da filosofia, mas como um levar,

et l'empirisme sceptique qui tire toutes les conséquences de l'interprétation psychologique du Cogito. Le premier courant a éliminé le motif du doute et la «réduction à l'Ego», l'autre se trompe grossièrement sur la nature de la subjectivité fondatrice et ruine toute vérité." Paul Ricœur, Á L'École de la Phénoménologie, Paris, J. Vrin, 1987, p. 46.

33 "Descartes hatte den reinsten Willen zu radikaler Vorurteilslosigkeit". Edmund Husserl, P. V, Husserliana, Band I, p. 9.

34 "Darin hat Descartes gefehlt, und so kommt es, daß er vor der größen aller Entdeckungen steht, sie in gewisser Wiese schon gemacht hat, und doch ihren eigentlichen Sinn nicht erfaßt, den Sinn der transzendentalen Subjektivität, und so das Eingangstor nicht übershreitet, das in die echte transzendentale Philosophie heineinleitet." Ibidem, pp. 9-10.

35 "Verführerische Verirrungen, in die Descartes und die Folgezeit verfallen sind, müssen wir dabei aufklären und vermeiden." E. Husserl, $C M$, Husserliana, Band I, $\S 2$, p. 8. 
pela fenomenologia, o cartesianismo à consumação da sua tendência interna mais estuante, enquanto esse consumar é também um trazer à plena posse de si mesma e à compreensão do seu autêntico significado toda a filosofia moderna que tem em Descartes o seu iniciador." ${ }^{\prime 36}$

\section{Considerações finais}

Poucos se atreverão a questionar a novidade da fenomenologia. Menos ainda duvidarão do seu imenso poder de reconfiguração da filosofia do século que passou. O problema reside, porém, na compreensão do teor dessa propalada novidade. É que não são menos os que consideram que a originalidade da proposta fenomenológica e das sucessivas ondas de choque que provocou nas ideias filosóficas, só assoma na sua plenitude se ela for sistematicamente devolvida aos gestos fundadores que, mais do que a precederem, são antes a expressão da sua mais genuína proveniência. Nesse sentido, uma mensagem "antiga" como é aquela de Descartes e Kant, sempre que se deixa reconduzir à sua expressão unitária e é, por essa via, reintegrada num horizonte de sentido mais amplo, assoma, quando novamente enunciada, como mensagem inteiramente nova, porque novas são também as circunstâncias que permitem interpretá-la. Esse juízo, foi dito, quando lê essas remissões de sentido como um puro retorno aos fundamentos converte-se num registo historicamente inadequado e factualmente incorrecto. Tal significa, pois, que qualquer tentativa para pensar o período das filosofias de Descartes e Kant como uma espécie de período de incubação da fenomenologia, ou como base subterrânea sobre a qual se projecta integralmente o edifício do fenomenológico, ancorado, de sua vez, na descoberta de sempre novas e cada vez mais amplas zonas de sobreposição, é um exercício compreensivelmente condenado ao insucesso. Não que a fenomenologia não possa, não deva ser pensada em relação com aqueles temas matriciais da filosofia que sistematicamente lhe prepararam o caminho. Mas que esse seja o caminho de uma reinterpretação de fundo desses momentos, capaz de os projectar para um patamar de sentido inteiramente novo e totalmente exaurido de manifestações unilaterais; que esse seja, em suma, o caminho de uma radicalização crescente, agenciado pelo lado da fenomenologia, que concretiza, enquanto promove a sua consumação plena, as promessas eternamente adiadas dos seus predecessores.

36 Pedro Alves, Subjectividade e Tempo na Fenomenologia de Husserl, Lisboa, Centro de Filosofia da Universidade de Lisboa, 2003, pp. 346-347. Esta leitura pode ser directamente surpreendida nos próprios textos de Husserl: "Sollte nicht die einzig fruchtbare Renaissance aber die sein, die die Cartesianischen Meditationen wiedererweckt: nicht sie zu übernehmen, sondern den tiefsten Sinn ihres Radikalismus im Rückgang auf das ego cogito allererst zu enthüllen und in weiterer Folge die von entsprießenden Ewigkeitswerte? [...] Jedenfalls bezeichnet sich damit der Weg, der zur transzendentalen Phänomenologie geführt hat." E. Husserl, CM, Husserliana, Band I, $\S 2$, p. 8 . 


\begin{abstract}
In this paper, we will consider the following isşue: the innovative dimension of E. Husserl's phenomenology repeatedly finds in the philosophies of Descartes and Kant a clear obstacle for its full comprehension. After all, is it not the case that the former discipline is just an extension of the perspectives stated by those earlier philosophers? But, to state the idea of a hidden phenomenology in the philosophies of Descartes and Kant has not, as its unavoidable counterpart, the dependence and the full commitment of Husserl's phenomenology with positive doctrines as the one sponsored by Descartes and Kant? And, if so, how can we rescue the idea of phenomenology as prima philosophia?
\end{abstract}


